\title{
Utilizing Difluorinated Thiophene Units To Improve the Performance of Polymer Solar Cells
}

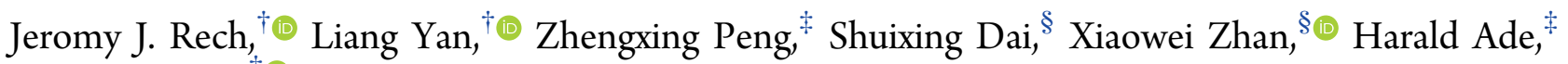 \\ and Wei You* ${ }^{*} \dagger$
}

\footnotetext{
${ }^{\dagger}$ Department of Chemistry, University of North Carolina at Chapel Hill, Chapel Hill, North Carolina 27599, United States

${ }^{\ddagger}$ Department of Physics and Organic and Carbon Electronics Lab (ORaCEL), North Carolina State University, Raleigh, North Carolina 27695, United States

${ }^{\S}$ Department of Materials Science and Engineering, College of Engineering, Key Laboratory of Polymer Chemistry and Physics of Ministry of Education, Peking University, Beijing 100871, China
}
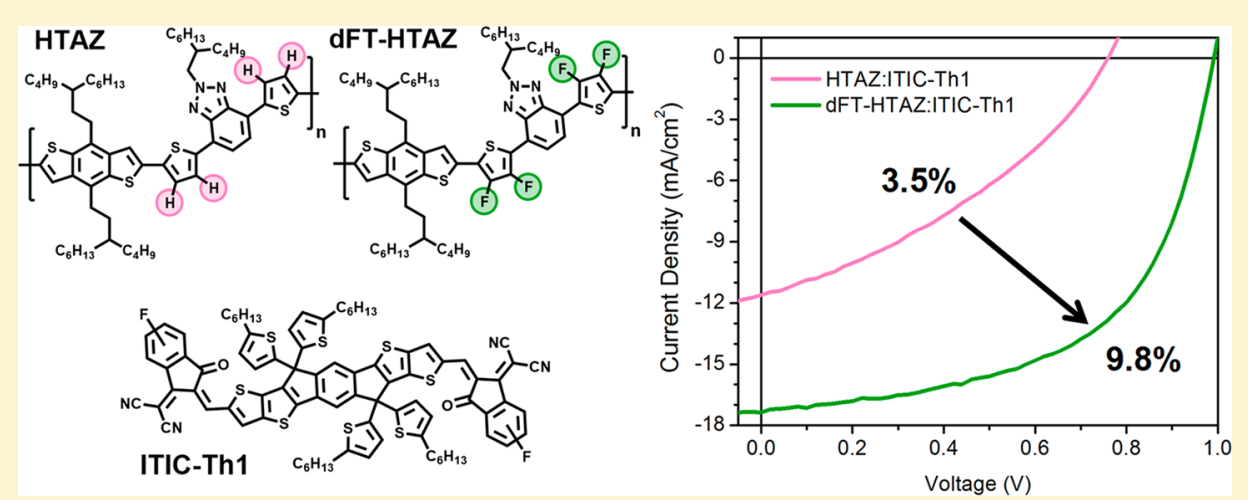

ABSTRACT: While there are numerous approaches to functionalize conjugated polymers for organic solar cells (OSCs), one widely adopted approach is fluorination. Of the many different locations for fluorination, one of the least studied is the conjugated linker which connects the donor and acceptor moieties; further, all existing reports primarily explore monofluorinated thiophene units. Herein, we synthesize and compare two conjugated polymers, HTAZ and dFT-HTAZ, which have different thiophene linkers. In HTAZ, a bare thiophene unit connects the donor and acceptor moieties, while dFTHTAZ utilizes difluorinated thiophene (dFT) linkers. These polymers serve as the model system to explore the impact of dFT units in OSCs; additionally, this is the first publication to investigate polymers containing dFT units paired with non-fullerene acceptors. Compared to HTAZ, the incorporation of the dFT units maintained the optical properties while lowering the energy levels by $\sim 0.4 \mathrm{eV}$, which allowed for a much improved $V_{\mathrm{oc}}$ value of $\sim 1 \mathrm{~V}$. Importantly, when compared with the appropriate non-fullerene acceptor, dFT-HTAZ:ITIC-Th1 blends reached an efficiency of $\sim 10 \%$, which is nearly $3 \times$ that of the nonfluorinated HTAZ. As most OSC polymers have thiophene linkers, using dFT units could serve as a proficient method to increase OSC performance in many polymer systems, especially those that do not have locations for functionalization on the acceptor moiety.

\section{INTRODUCTION}

Organic solar cells (OSCs) based on conjugated polymers have been extensively researched for reasons that include low cost, flexibility, lightweight, semitransparency, and ease of processing on an industrial scale, making them candidates to supply the world's renewable energy needs. ${ }^{1-4}$ The continued efficiency improvements for OSCs is due in part to the development of new conjugated organic materials and blending strategies (e.g., ternary blend), ${ }^{5-9}$ and a both popular and reliable method to improve device efficiency is fluorination of conjugated polymers. ${ }^{10-15}$ Fluorine is both the smallest electron-withdrawing group (van der Waals radius of $1.35 \AA$ ) and the most electronegative element $\left(\chi_{\mathrm{r}}=3.98\right){ }^{16-18}$ Therefore, when added along the polymer backbone, fluorine offers negligible steric hindrance and deepens energy levels, while maintaining a similar band gap. ${ }^{18-20}$ Another advantage to fluorination is an increase in inter- and intramolecular interactions (e.g., $\mathrm{F} \cdots \mathrm{H}, \mathrm{F} \cdots \mathrm{S}$, and $\mathrm{F} \cdots \pi$ ), which have demonstrated to favorably change the polymer backbone planarity as well as the packing in OSC devices. ${ }^{21-25}$ Most high performance conjugated polymers used in OSCs are copolymers with a characteristic "donor-linker-acceptorlinker" alternating architecture; therefore, the location of fluorination needs to be considered.

Received: June 6, 2019

Revised: August 5, 2019

Published: August 22, 2019 
While the donor moiety can be fluorinated to improve the photovoltaic performance of the devices, in many cases, adding fluorine substituents to the donor moiety shows a detrimental impact in device performance. ${ }^{12,26}$ However, one fluorinated donor moiety that has consistently performed well is $3,3^{\prime}$ difluoro-2,2'-bithiophene (2TF). ${ }^{27-36}$ Compared to a nonfluorinated bithiophene donor moiety, the $2 \mathrm{TF}$ has been shown to have a higher torsional barrier, which promoted a planar structure with enhanced $\pi-\pi$ interactions, and results in improved morphology of the bulk heterojunction blend and photovoltaic properties of the corresponding devices. ${ }^{31,33}$ There have also been a few studies that investigated the fluorination of the solubilizing side chains of conjugated polymers. Therein fluorination seems to generally increase mobilities, suppress triplet formation and charge recombination, and slightly improve thermal stability, which can be attributed in all cases to fluorine interactions increasing ordering of the side chains into a more optimal orientation. ${ }^{37-42}$ However, because of the limited scope of materials made with fluorinated side chains, a complete understanding on the impact of this approach is still elusive. Given the electron-withdrawing nature of fluorine, it is not surprising that the most common fluorination location is the electrondeficient acceptor moiety. We have previously demonstrated with our FTAZ polymer that the fluorine substituent on the benzotriazole acceptor moiety increased all three major device characteristics: open circuit voltage $\left(V_{\text {oc }}\right)$, short circuit current density $\left(J_{\mathrm{sc}}\right)$, and fill factor $(F F) .{ }^{10,11}$ The increase in $V_{\mathrm{oc}}$ was due to the deepening of the highest occupied molecular orbital (HOMO) level from the electron-withdrawing strength of the fluorine substituent, and a higher hole mobility allowed for improvements in both $J_{\mathrm{sc}}$ and FF. This same trend has been demonstrated by many other polymer systems as well. ${ }^{43-47}$

While fluorination of the acceptor moiety has been established as a valuable technique to increase the OSC device performance, a limitation of this approach is that not all acceptor moieties have locations for fluorination. A notable example would be the benzodithiophenedione (BDD) acceptor moiety in the commonly used PBDB-T polymer. ${ }^{48}$ Moreover, to synthesize a new fluorinated acceptor moiety, typically a new synthetic route needs to be developed beginning with a fluorinated starting material; this de novo synthesis increases the number of steps/time required to make the final polymer. Therefore, to circumvent these issues, fluorination on one final location should be considered: the conjugated linker (often thiophene) that connects the donor and acceptor moieties together. The idea of fluorinating thiophene units has shown success in the donor moiety of $2 \mathrm{TF}$ (vide supra) and in various monofluorinated thiophene units ( $3^{\prime} \mathrm{FT}$ and $4^{\prime} \mathrm{FT}$ ) which we used to link benzodithiophene donor moieties and benzotriazole acceptor moieties. ${ }^{21}$ Therein, we demonstrated that relocating the fluorine substituent from acceptor moiety to the thiophene linker maintained the advantageous properties from fluorination. There have been multiple other reports that have explored using monofluorinated thiophene units, ${ }^{17,49}$ but there are very few reports for OSC polymers that simultaneously utilize fluorination at both the $3^{\prime}$ - and $4^{\prime}$-position of the thiophene linker, i.e., a difluorinated thiophene (dFT) unit.

Throughout the literature, $\mathrm{dFT}$ units have a prominent place in the realm of organic field-effect transistors (OFETs). There are numerous reports that utilize $\mathrm{dFT}$ units in conjugated polymers to achieve high OFET mobilities. ${ }^{24,50-58}$ For example, Hu's lab reported an OFET polymer containing dFT units with mobilities over $6 \mathrm{~cm}^{2} \mathrm{~V}^{-1} \mathrm{~s}^{-1}$ and on/off ratio over $10^{5}$, which makes it among the highest values in OFETs fabricated on a flexible substrate. ${ }^{59}$ However, of the reports that use dFT units in OSCs, ${ }^{60-65}$ the impact of fluorination remains ambiguous. For example, Takimiya's lab used a difluorinated thiophene unit in their PNTz polymers, and compared to the monofluorinated version, there was a sharp decrease in performance $(10.5 \%$ vs $6.5 \%)$, which is attributed to increased recombination - the polymers containing the dFT unit had a much lower solubility and thus formed crystallites. ${ }^{60}$ Conversely, when Heeney's lab incorporated the dFT unit into their germanium-containing polymers, they observed a 50\% improvement in efficiency, attributed to a substantially higher hole mobility and deeper energy levels. ${ }^{61,62}$ Furthermore, there have not been any reports of a dFT-containing conjugated polymer that was paired with non-fullerene acceptors (NFAs), even as NFAs have rapidly boosted the performance of OSCs within the past few years. ${ }^{6-71}$

To further understand the impact of fluorination, in particular, the dFT unit, we designed and synthesized a new conjugated polymer, dFT-HTAZ, which differs from the original HTAZ polymer ${ }^{10}$ by having two difluorinated thiophene linkers (see Scheme 1 for structures of HTAZ and dFT-HTAZ). The incorporation of the dFT units maintained the optical properties while lowering the energy levels of the dFT-HTAZ polymer by $\sim 0.4 \mathrm{eV}$, which allowed for a much improved $V_{\text {oc }}$ value of $\sim 1 \mathrm{~V}$ in the dFT-HTAZ based devices. While multiple electron acceptors were considered and tested, the champion device of dFT-HTAZ:ITIC-Th1 reached an efficiency of $\sim 10 \%$, which is nearly $3 \times$ that of the nonfluorinated HTAZ:ITIC-Th1 blend. As most OSC polymers have thiophene linkers, we envision that strategically using the dFT units can serve as an effective method to increase OSC performance in many conjugated polymer systems.

\section{RESULTS AND DISCUSSION}

2.1. Synthesis of Monomers and Polymers. HTAZ was synthesized according to literature procedures, ${ }^{10,21}$ and the synthetic pathway for dFT-HTAZ is depicted in Scheme 1. The starting material, tetrabromothiophene (1), can be prepared straightforwardly by reacting thiophene with excess liquid bromine; however, recrystallization is necessary before the next reaction can proceed. As the desired locations for fluorination is on the less reactive $3^{\prime}$ - and $4^{\prime}$-positions of thiophene, 1 must first be protected at the $2^{\prime}$ - and $5^{\prime}$-positions with trimethylsilyl (TMS) groups to render 2 . Once purified, 2 was then treated with $n$-butyllithium $(n-\mathrm{BuLi})$ and underwent electrophilic fluorination with $N$-fluorobenzenesulfonimide (NFSI) to offer 3; however, the order of addition is very important. Upon addition of $2 \mathrm{~mol}$ equiv of $n-\mathrm{BuLi}$, then 2 equiv of NFSI resulted in unacceptably low yields $(<10 \%)$. Fortunately, we discovered that the yield for this reaction could be improved by adding a small amount of $n$-BuLi and NFSI in several portions rather than all at once. Multiple different orders of addition were explored and are summarized in the Supporting Information. Next, selective deprotection and bromination of the 5 '-position of 3 can be achieved in one pot with $\mathrm{N}$-bromosuccinimide (NBS). The desired precursor 4 can then be made through lithium-halogen exchange followed by stannylation. Product 4 is a key immediate, since it can be paired with any acceptor moiety of choosing via Stille coupling. 
Scheme 1. Synthesis of the Fluorinated Thiophene Units, Monomers, and Stille Coupling Based Polymerization To Make HTAZ and dFT-HTAZ Polymers

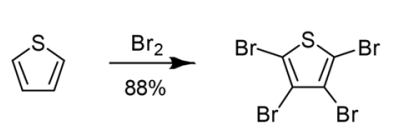

(1)

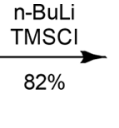<smiles>Cc1sc(S(C)(=O)=O)c(Br)c1Br</smiles>

(2)

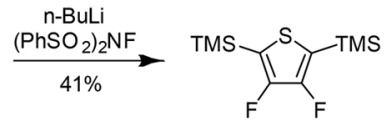

(3)

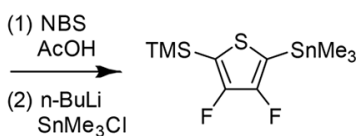

$93 \% \quad(4)$<smiles>CSc1sc(S(C)(=O)=O)c(F)c1F</smiles>

(4)

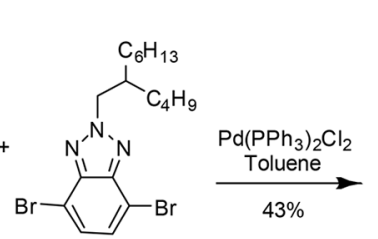

(5)

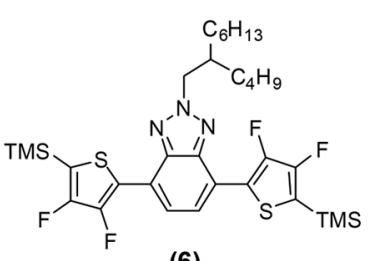

(6)
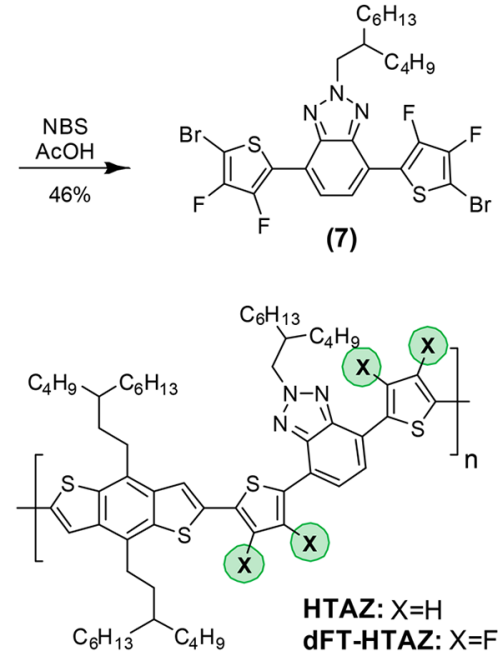

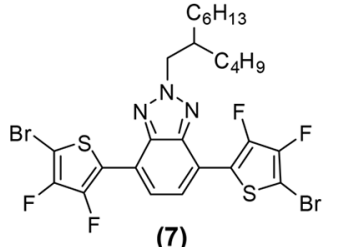

(7)

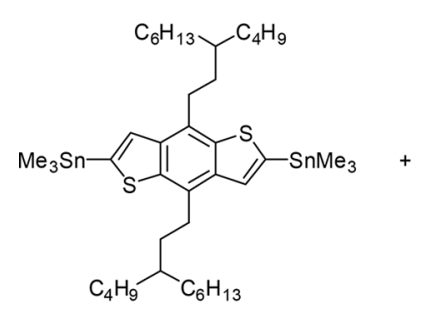

(BnDT monomer)

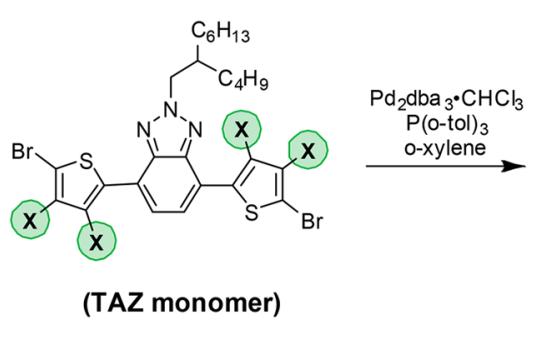

In our case, the fluorinated thiophene units were attached through a Stille cross-coupling reaction between 4 and a brominated benzotriazole 5 to yield the monomer precursor 6 . The final step to produce the dFT-HTAZ monomer 7 is to remove the TMS protecting group and brominate at that location, which can be done similarly to step 1 in converting 3 to 4 . The resulting monomer was recrystallized multiple times to yield a high purity yellow crystalline powder appropriate for polymerization. Finally, the monomers (TAZ monomer and BnDT monomer) were subjected to a microwave assisted Stille polycondensation to yield the target polymers HTAZ and dFT-HTAZ. Full details for each reaction, nuclear magnetic resonance (NMR) characterization, and polymerization conditions are described in the Supporting Information. The number-average molar mass $\left(M_{n}\right)$ and dispersities $(\nexists)$, reported in Table 1, were acquired through high-temperature gel permeation chromatography (HT-GPC) at $150{ }^{\circ} \mathrm{C}$ with 1,2,4-trichlorobenzene (TCB) (stabilized with $125 \mathrm{ppm} \mathrm{BHT)}$ as the eluent. Both polymers have $M_{\mathrm{n}}$ values appropriate for high current density while remaining soluble; the dispersity values are also appropriate for such step growth polymerization methods.

2.2. Optical and Electrochemical Properties. To understand the impact of the dFT units, we first looked at variations in the optical and electrochemical properties of the resulting polymers. First, the optical properties of the polymers HTAZ and dFT-HTAZ were compared with solution UV-vis absorption of the polymer dissolved in chloroform in Figure 1a. Both polymers absorb in the same range and have an absorption onset at $618 \mathrm{~nm}$, which equates to an optical band gap of $2.01 \mathrm{eV}$. While the HTAZ polymer shows a slightly stronger aggregation shoulder around $580 \mathrm{~nm}$, both polymers have a similar $\lambda_{\max }$ around $535 \mathrm{~nm}$. When thin films of polymers are deposited via spin-coating, similar results are seen in the absorption when comparing HTAZ and dFT-HTAZ (Figure 1b). In short, with the exception of a slight difference in aggregation strength, both polymers have very similar optical properties.

Next we estimated the highest occupied molecular orbital (HOMO) and lowest unoccupied molecular orbital (LUMO) energy levels by cyclic voltammetry $(\mathrm{CV})$ of a thin polymer film for both polymers (Figure 1c showing the voltammograms). Full details for the $\mathrm{CV}$ setup can be found in the Supporting Information. Key optical and electrochemical data are summarized in Table 1. Unlike the optical properties, there are large differences when comparing the electrochemical properties of the two polymers. First, the conversion of oxidation onset $\left(E_{\mathrm{OX}}\right)$ to HOMO energy level is done through the ferrocene standard $\left(E_{\mathrm{FC}}\right)$ by using the equation $\mathrm{HOMO}=$ $-\left(4.8 \mathrm{eV}+e\left(E_{\mathrm{OX}}-E_{\mathrm{Fc}_{\mathrm{Fc}}+}\right)\right)$. The HTAZ polymer has an oxidation onset of $0.72 \mathrm{~V}$, which corresponds to a $\mathrm{HOMO}$ energy level of $-5.44 \mathrm{eV}$, while the dFT-HTAZ polymer is shifted to an oxidation onset of $1.11 \mathrm{~V}$, corresponding to a HOMO energy level of $-5.78 \mathrm{eV}$. The LUMO was estimated through the optical band gap, and using the information learned from the optical and electrochemical properties, we can construct an approximate energy level diagram for the devices, as shown in Figure 1d. In comparison, it is clear that the addition of the electron-withdrawing fluorine substituents to the thiophene linkers lowers the HOMO energy levels by $\sim 0.4 \mathrm{eV}$. The deeper HOMO energy level is advantageous as the $V_{\text {oc }}$ is linked to the energy level difference between the HOMO and LUMO levels of the donor and acceptor materials. Lowering the HOMO level of HTAZ by an additional $0.4 \mathrm{eV}$ would indicate that the dFT-HTAZ based photovoltaic devices should have a much larger $V_{\text {oc }}$ than that of the HTAZ based ones.

2.3. Photovoltaic Properties. To determine the efficacy of the fluorinated thiophene units as a means to improve device efficiency, the photovoltaic properties were next investigated in a bulk heterojunction ( $\mathrm{BHJ}$ ) solar cell with a normal device configuration: ITO/CuSCN/dFT HTAZ:PCBM/Ca/Al and ITO/PEDOT:PSS/HTAZ:PCBM/ 
Table 1. Molar Mass, Optical Properties, Band Gaps, and Measured Energy Levels for Both HTAZ and dFT-HTAZ Polymers

\begin{tabular}{lccccccc}
\multicolumn{1}{c}{ polymer } & $M_{\mathrm{n}}{ }^{a}(\mathrm{~kg} / \mathrm{mol})$ & $Ð\left(M_{\mathrm{w}} / M_{\mathrm{n}}\right)$ & $\lambda_{\text {max,sol }}{ }^{b}(\mathrm{~nm})$ & $\lambda_{\max , \mathrm{fllm}}{ }^{c}(\mathrm{~nm})$ & $E_{\mathrm{g}, \mathrm{opt}}{ }^{d}(\mathrm{eV})$ & $\mathrm{HOMO}^{e}(\mathrm{eV})$ & $\mathrm{LUMO}^{f}(\mathrm{ev})$ \\
HTAZ & 44.1 & 3.0 & $535 / 570$ & $537 / 580$ & 2.01 & -5.44 & -3.43 \\
dFT-HTAZ & 59.2 & 2.1 & 534 & 530 & 2.01 & -5.78 & -3.77
\end{tabular}

${ }^{a}$ Measured by high-temperature gel permeation chromatography. ${ }^{b}$ Absorption maximum in chloroform solution. ${ }^{c}$ Absorption maximum in thin film. ${ }^{d}$ Optical band gap is found by dividing 1240 by the absorption onset (618 nm for both polymers). ${ }^{e}$ Measured by cyclic voltammetry.

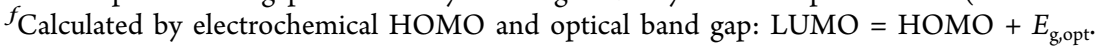
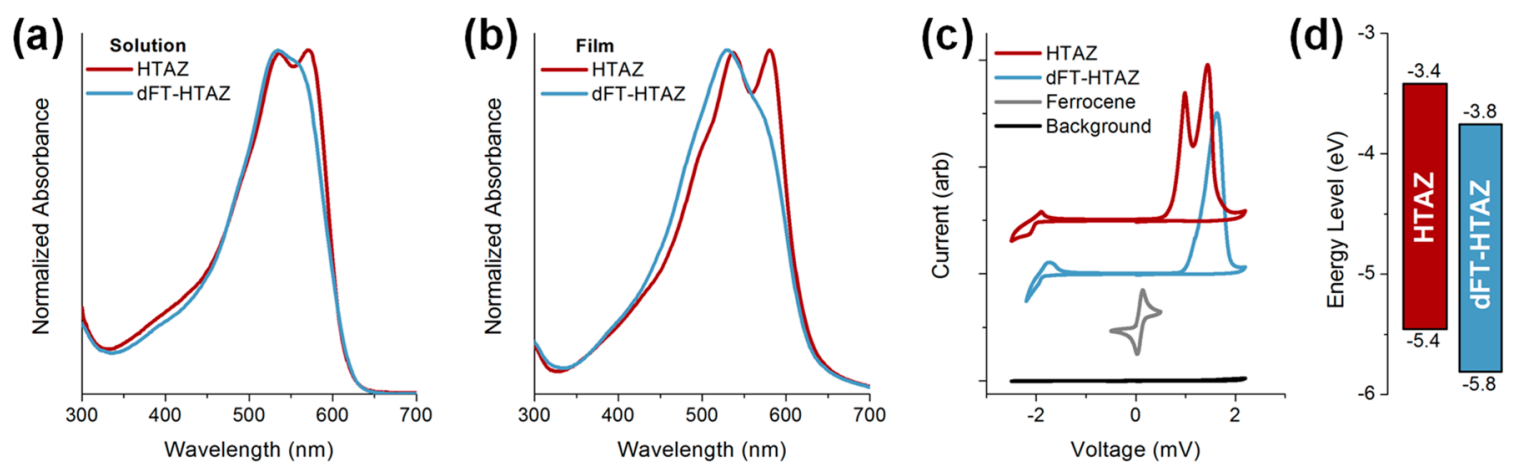

Figure 1. Normalized UV-vis spectra of the HTAZ and dFT-HTAZ polymers (a) in chloroform solution and (b) as thin films cast from chlorobenzene. (c) Cyclic voltammogram of each polymer as a thin film, with a scan rate of $0.1 \mathrm{~V} \mathrm{~s}^{-1}$. (d) Energy levels of both polymers calculated from cyclic voltammetry.

$\mathrm{Ca} / \mathrm{Al}$. The polymer:PCBM ratio was $1: 2$, and the active layer thickness was $\sim 250 \mathrm{~nm}$ for both types of devices. The solar cell characteristics are shown in Table 2 , and a representative $J-V$ curve is found in Figure 2a, with different optimization conditions summarized in Table S1. Note that we used two different hole transport layers (HTLs): PEDOT:PSS and $\mathrm{CuSCN}$. Given the low HOMO energy level of the dFTHTAZ polymer, $\mathrm{CuSCN}$, which has the more appropriate work function $(5.5 \mathrm{eV}),{ }^{72}$ was chosen as the HTL for dFTHTAZ based devices. The HTAZ polymer blend used PEDOT:PSS at the HTL, as it had a more appropriate work function $(5.1 \mathrm{eV})$. To illustrate the impact of the HTL, the dFT-HTAZ polymer was also tested with PEDOT:PSS, and the results are shown in Figure S4. While similar $V_{\mathrm{oc}}$ and $J_{\mathrm{sc}}$ are obtained, there is a drastic difference in the FF $(41.7 \%$ vs $62.9 \%)$, which is attributed to the energy level misalignment with the PEDOT:PSS interlayer.

Consistent with the prediction above, the $V_{\mathrm{oc}}$ value for the dFT-HTAZ blend is significantly improved when compared to the HTAZ devices as the HOMO energy level of dFT-HTAZ is deepened upon addition of the fluorine substituents. Specifically, the $V_{\text {oc }}$ of HTAZ is $0.741 \pm 0.001 \mathrm{~V}$ while dFTHTAZ has a $V_{\text {oc }}$ of $0.990 \pm 0.002 \mathrm{~V}$. A strong increase in $V_{\text {oc }}$ is often seen upon fluorination, and this increase of $0.25 \mathrm{~V}$ in $V_{\mathrm{oc}}$ shows the same trends continue to hold when the fluorination occurs on the thiophene linker. It is important to note that the energy levels measured by $\mathrm{CV}$ would suggest a $0.4 \mathrm{~V}$ change in the $V_{\text {oc }}$ value, meaning there is $\sim 0.15 \mathrm{~V}$ additional energy loss exists in the dFT-HTAZ:PCBM blend. This energy loss is likely from either a change in the CT state energy, which can be attributed to a change at the donor/acceptor interfacial morphology, or a change in charge recombination loss. Regardless, while the $V_{\text {oc }}$ loss appear to be $\sim 0.1 \mathrm{~V}$ higher for the dFT-HTAZ blends, the larger increase in $V_{\text {oc }}$ results in a net improvement in the performance of the dFT-HTAZ blends. Next, the $J_{\mathrm{sc}}$ is often related to the absorption spectra of the polymers, which, as highlighted previously, are nearly identical for HTAZ and dFT-HTAZ. Yet, the HTAZ polymer has a slightly higher $J_{\mathrm{sc}}\left(11.10 \pm 0.25 \mathrm{~mA} / \mathrm{cm}^{2}\right)$ than $\mathrm{dFT}$ HTAZ $\left(9.74 \pm 0.33 \mathrm{~mA} / \mathrm{cm}^{2}\right)$. Finally, the $F F$ is increased, from $53.3 \pm 1.3 \%$ for HTAZ to $61.9 \pm 1.4 \%$ for dFT-HTAZ. Our previous work has shown that the increasing of hole mobility through fluorination strongly influences the $F F^{10,20,73}$ which can be attributed to the more planar backbone. To confirm the difference in backbone planarity, we performed density functional theory (DFT) calculations at the DFT B3LYP/6-311+G(d) level of theory on one repeat unit for both HTAZ and dFT-HTAZ, the results of which are shown in Figure S3. The fluorination of the thiophene linker has a large impact on the most stable conformation and the dihedral angle between units. The dFT-HTAZ polymer has a conformation that is very planar, with the largest dihedral angle of $0.2^{\circ}$, while the HTAZ polymer has a significantly larger dihedral angle of $11.6^{\circ}$ between the BnDT donor moiety and the thiophene linker. This change in the backbone planarity can be facilitated through noncovalent inter- and intramolecular interactions, such as $\mathrm{F} \cdots \mathrm{H}, \mathrm{F} \cdots \mathrm{S}$, and $\mathrm{F} \cdots \pi$; the fluorinated thiophene units can impart the same interactions, thus explaining the increase in FF from 53.3 to $61.9 \%$. The impact on mobility is also directly measured through space charge limited current (SCLC) measurements (Figure S5 and Table S2). The hole mobility value for the dFT-HTAZ:PCBM blend $\left(15.5 \times 10^{-4}\right.$ $\left.\mathrm{cm}^{2} \mathrm{~V}^{-1} \mathrm{~s}^{-1}\right)$ is nearly a magnitude higher than the HTAZ:PCBM blend $\left(1.70 \times 10^{-4} \mathrm{~cm}^{2} \mathrm{~V}^{-1} \mathrm{~s}^{-1}\right)$, which is attributed to the more planar backbone from the dFT units as demonstrated above. In summary, when paired with PCBM, the HTAZ blends can reach a PCE of $4.40 \%$ while dFT-HTAZ can achieve a higher value over $6.41 \%$, a very large $46 \%$ increase in efficiency, mainly due to much improved $V_{\mathrm{oc}}$ and FF.

While these device results show an optimistic outlook for fluorinated thiophene units, fullerene electron acceptors, such as PCBM, have been rapidly replaced with the new nonfullerene acceptors (NFAs). Compared to PCBM, these new NFAs, such as ITIC and ITIC-Th1 shown in Chart 1 , have superior light absorption in the visible and near-infrared range 
Table 2. Photovoltaic Parameters of Organic Solar Cells for Each Polymer (HTAZ and dFT-HTAZ) Paired with Various Acceptors (PCBM, ITIC, and ITIC-Th1)

\begin{tabular}{|c|c|c|c|c|c|c|c|}
\hline donor & acceptor & $J_{\mathrm{sc}}\left(\mathrm{mA} / \mathrm{cm}^{2}\right)$ & $V_{\mathrm{oc}}(\mathrm{V})$ & $F F(\%)$ & PCE (\%) & $\mathrm{PCE}_{\max }(\%)$ & $J_{\text {calc }}\left(\mathrm{mA} / \mathrm{cm}^{2}\right)$ \\
\hline \multirow[t]{3}{*}{ HTAZ } & PCBM & $11.10 \pm 0.25$ & $0.741 \pm 0.001$ & $53.3 \pm 1.3$ & $4.39 \pm 0.17$ & 4.40 & 10.40 \\
\hline & ITIC $^{11}$ & $12.54 \pm 0.49$ & $0.851 \pm 0.001$ & $39.9 \pm 0.9$ & $4.26 \pm 0.24$ & & \\
\hline & ITIC-Th1 & $11.77 \pm 0.72$ & $0.749 \pm 0.010$ & $35.8 \pm 1.2$ & $3.16 \pm 0.29$ & 3.54 & \\
\hline \multirow[t]{3}{*}{ dFT-HTAZ } & PCBM & $9.74 \pm 0.33$ & $0.990 \pm 0.002$ & $61.9 \pm 1.4$ & $5.97 \pm 0.28$ & 6.41 & 9.08 \\
\hline & ITIC & $6.39 \pm 0.35$ & $0.973 \pm 0.008$ & $42.7 \pm 1.1$ & $2.66 \pm 0.20$ & 2.92 & \\
\hline & ITIC-Th1 & $16.12 \pm 0.97$ & $0.991 \pm 0.002$ & $57.1 \pm 0.6$ & $9.12 \pm 0.49$ & 9.76 & 16.38 \\
\hline
\end{tabular}
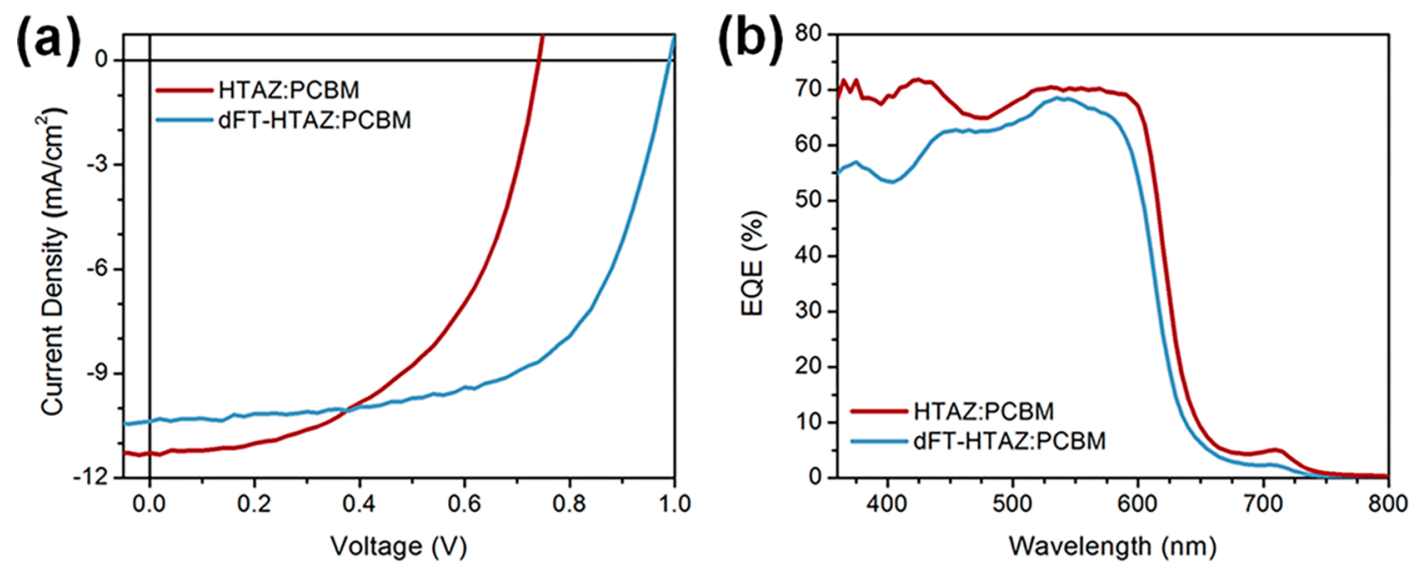

Figure 2. (a) Representative $J-V$ curve for HTAZ:PCBM and dFT-HTAZ:PCBM devices with (b) corresponding EQE responses.

and high levels of tunability in optoelectronic properties. ${ }^{66-69}$ More importantly, these advantages have pushed OSC performance surpassing $16 \%{ }^{74}$ Because of the rapid growth and use of NFAs, we next paired the polymers with common high performance acceptors ITIC and ITIC-Th1 to see whether the same improvements are found when comparing the different thiophene linkers.

The effectiveness of the fluorinated thiophene units in NFA blends is next explored. First, the photovoltaic properties were investigated with inverted configuration solar cell: $\mathrm{ITO} / \mathrm{ZnO} /$ dFT-HTAZ:acceptor $/ \mathrm{MoO}_{3} / \mathrm{Al}$. For the NFA based devices, the polymer:acceptor ratio was changed to $1: 1$, and the active layer thicknesses were between 75 and $100 \mathrm{~nm}$. As shown in the representative $J-V$ curve in Figure 3a, the high $V_{\text {oc }}$ value of $\sim 1 \mathrm{~V}$ is maintained for all three blends, but there are very large differences in the $J_{s c}$ and FF. Interestingly, the dFTHTAZ:ITIC blend has very poor performance compared to the dFT-HTAZ:PCBM blend, suffering from very low $J_{\text {sc }}$ and FF. While this seems unexpected, as ITIC has shown great performance with many other $\mathrm{BHJ}$ blends, the energy levels of each component (shown in Figure 3b) illustrates an important issue-dFT-HTAZ:ITIC forms a type I heterojunction instead of the conventional type II heterojunction. The HOMO energy level of the ITIC molecule $(-5.6 \mathrm{eV})$ is higher than the HOMO energy level of the dFT-HTAZ polymer $(-5.8 \mathrm{eV})$, which can lead to the formation of traps and thus erode the performance. Just as the CuSCN HTL was needed instead of the more common PEDOT:PSS HTL in the conventional architecture when paired with PCBM, the dFT-HTAZ polymer has such a deep HOMO energy level from the fluorine substituents that the other components (e.g., the pairing NFA) need to be carefully considered to obtain an ideal energetic landscape.

To realize the benefits of the dFT units, an acceptor with a deeper HOMO energy level needs to be used. Therefore, by use of the same fluorination theme, a fluorinated derivative of ITIC called ITIC-Th1 was next explored. ${ }^{75,76}$ Compared to ITIC, the ITIC-Th1 acceptor has thienyl instead of phenyl side chains and a fluorinated end group; these changes can decrease the HOMO energy level to match that of dFT-HTAZ and form an effective type II heterojunction. Upon comparison of the dFT-HTAZ:PCBM and dFT-HTAZ:ITIC-Th1 blends, there is a very large increase in the $J_{\mathrm{sc}}$ from $9.74 \pm 0.33$ to $16.12 \pm 0.97 \mathrm{~mA} / \mathrm{cm}^{2}$, respectively. This large $66 \%$ increase in the $J_{\mathrm{sc}}$ is attributed to the extra complementary absorbance of the ITIC-Th1 acceptor, which is best illustrated in the EQE response in Figure 3c. In the wavelengths of 400-650 nm, the response is primarily from the dFT-HTAZ polymer, which remains unchanged in the different blends; however, the ITICTh1 has strong absorbance in the visible and near-infrared range and contributes to the absorbance values out to $\sim 800$ $\mathrm{nm}$. This extra $\sim 150 \mathrm{~nm}$ worth of harvestable photons helps increase the $J_{\mathrm{sc}}$ compared to the PCBM acceptor, which primarily absorbs higher energy UV light. When comparing the FF of the dFT-HTAZ:PCBM $(61.9 \pm 1.4 \%)$ blend with dFTHTAZ:ITIC-Th1 $(57.1 \pm 0.6 \%)$, there is a slight decrease in value. While the overall PCE is much higher (9.76\% vs $6.41 \%)$, driven by the much improved $J_{s c}$ we studied the morphology of the active layer to better understand the $\mathrm{BHJ}$ blend films and the decrease in FF for the dFT-HTAZ:ITIC-Th1 blend.

2.4. Morphology. We began our study of morphology with measuring the texture and molecular packing of the materials through synchrotron radiation based grazing incidence wideangle X-ray scattering (GIWAXS). ${ }^{97}$ The 2D GIWAXS patterns for neat dFT-HTAZ films cast from chlorobenzene with 3\% 1,8-diiodooctane additive (CB + DIO) and toluene (TOL) solvents are shown in Figures $4 \mathrm{a}$ and $4 \mathrm{~b}$. Neat films of ITIC-Th1 cast from toluene can also be found in the Supporting Information (Figure S6). Also, the blend films of dFT-HTAZ with both PCBM and ITIC-Th1 are shown in the 
Chart 1. Chemical Structures for the Three Electron Acceptors Used in the Publication: PCBM, ITIC, and ITIC-Th1
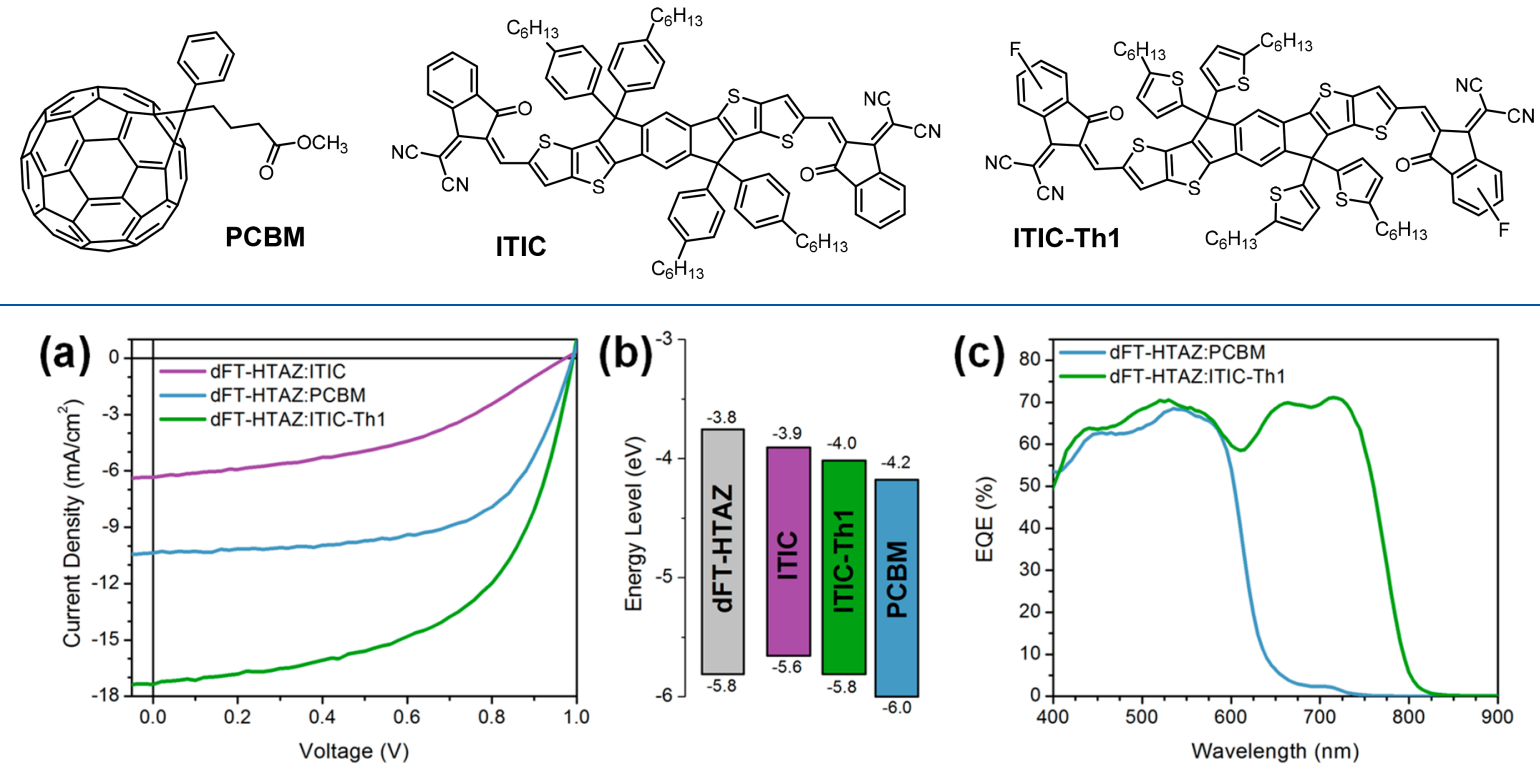

Figure 3. (a) Representative $J-V$ curves for dFT-HTAZ:acceptor blends, (b) HOMO/LUMO energy levels as measured through CV, and (c) $\mathrm{EQE}$ response for various blends.

2D GIWAXS patterns in Figures 4c and 4d. The corresponding in-plane (dotted lines) and out-of-plane (solid lines) profile for each pattern is shown in Figure 4e. Upon comparison of the neat dFT-HTAZ films with different solvents, the dFT-HTAZ cast from $\mathrm{CB}+\mathrm{DIO}$ shows higher order lamellar (h00) including (100) at $q=0.32 \AA^{-1},(200)$ at $q=0.66 \AA^{-1},(300)$ at $q=0.99 \AA^{-1}$, and another set of peaks with the first-order peak $q=0.46 \AA^{-1}$ and the second-order peak at $q=0.92 \AA^{-1}$. There is also a strong out-of-profile $(010) \pi-\pi$ stacking peak at $q=1.73 \AA^{-1}$, which corresponds to a real-space packing distance of 3.63 Å. Comparatively, when dFT-HTAZ was cast from toluene, while having a favorable face-on packing, the resulting neat film has lower order, only being able to resolve peaks of $(100)$ at $q=0.32 \AA^{-1}$ and (200) at $q=0.65 \AA^{-1}$. Additionally, the (010) $\pi-\pi$ stacking peak shifts to $q=1.67$ $\AA^{-1}$, which corresponds to a larger distance of $3.76 \AA$. This suggests that dFT-HTAZ has higher molecular ordering when cast from the $\mathrm{CB}+\mathrm{DIO}$ solvent compared to toluene.

Interestingly, when blended with the appropriate electron acceptor, the dFT-HTAZ:PCBM blend, which was cast from $\mathrm{CB}+\mathrm{DIO}$, shows reduced molecular ordering compared to the neat film, and the dFT-HTAZ:ITIC-Th1 blend, which was cast from toluene, shows much improved molecular packing compared to the neat film. The more crystalline dFTHTAZ:ITIC-Th1 film shows higher order (h00) peaks: (100) at $q=0.33 \AA^{-1},(200)$ at $q=0.66 \AA^{-1},(300)$ at $q=$ $0.99 \AA^{-1}$, and one more set of peaks with first-order peak at $q=$ $0.46 \AA^{-1}$ and the second-order peak at $q=0.92 \AA^{-1}$. This suggests that PCBM suppresses the packing of the dFT-HTAZ in the blend while ITIC-Th1 can improve it, which is important as the higher ordering of dFT-HTAZ in the dFTHTAZ:ITIC-Th1 blend is beneficial for the charge transport in the polymer-rich domains. Another difference comes from the (010) peak position when blended with the electron acceptor. For dFT-HTAZ:ITIC-Th1, there is a strong (010) $\pi-\pi$ stacking peak at $q=1.78 \AA^{-1}$, which corresponds to a realspace packing distance of $3.53 \AA$. The dFT-HTAZ:PCBM blend has a much larger (010) $\pi-\pi$ stacking peak which corresponds to a real space packing distance of $3.76 \AA$. Through the full width at half-maximum of the (010) peaks, found through fitting with pseudo-Voigt functions and shown in Figure S8, the coherence length can be calculated, and the dFT-HTAZ:PCBM blend has a much smaller coherence length of $9.1 \AA$ compared to the $35.3 \AA$ value for the dFTHTAZ:ITIC-Th1 blend. Blends of dFT-HTAZ:ITIC-Th1 have both a smaller $\pi-\pi$ stacking distance and much longer coherence length (nearly $4 \times$ longer), both of which are beneficial for charge transport and help contribute to the much higher $J_{\text {sc }}$ compared to the PCBM blend.

We next applied resonant soft X-ray scattering (RSoXS $)^{78}$ to compare the domain purity and spacing for the two blends (dFT-HTAZ:PCBM and dFT-HTAZ:ITIC-Th1). The thickness-normalized and Lorentz-corrected RSoXS profiles are shown in Figure S7, and the real-space domain spacing (termed long period) and the relative root-mean-square composition variation (referring to previously reported average domain purity) resolved from RSoXS are shown in Table 3. The analysis procedures and meaning of these morphological parameters were well discussed in our recent publication. ${ }^{79}$ Both blends have a very similar peak position at $q \sim 0.18 \mathrm{~nm}^{-1}$ $\left(0.181 \mathrm{~nm}^{-1}\right.$ for PCBM blend and $0.175 \mathrm{~nm}^{-1}$ for ITIC-Th1 blend), which corresponds to a similar long period of $\sim 35 \mathrm{~nm}$. The relative root-mean-square (RMS) composition, related to domain purities, is 1 and 0.73 for dFT-HTAZ:PCBM and dFT-HTAZ:ITIC-Th1, respectively. The higher RMS composition of dFT-HTAZ:PCBM can help explain the higher FF compared to the dFT-HTAZ:ITIC-Th1 blend, as impure domains can lead to increased bimolecular recombination and thus reduce the $F F^{80}$

We have previously published the morphology of HTAZ with both fullerene and non-fullerene acceptors, and generally amorphous packing is observed with both. ${ }^{11,73,81}$ Both the (100) and (010) peaks are broad peaks, thus shorter coherence lengths and a higher degree of disorder compared to dFTHTAZ. Furthermore, the long period for non-fullerene blends, such as HTAZ:ITIC, shows larger domain spacing values of 

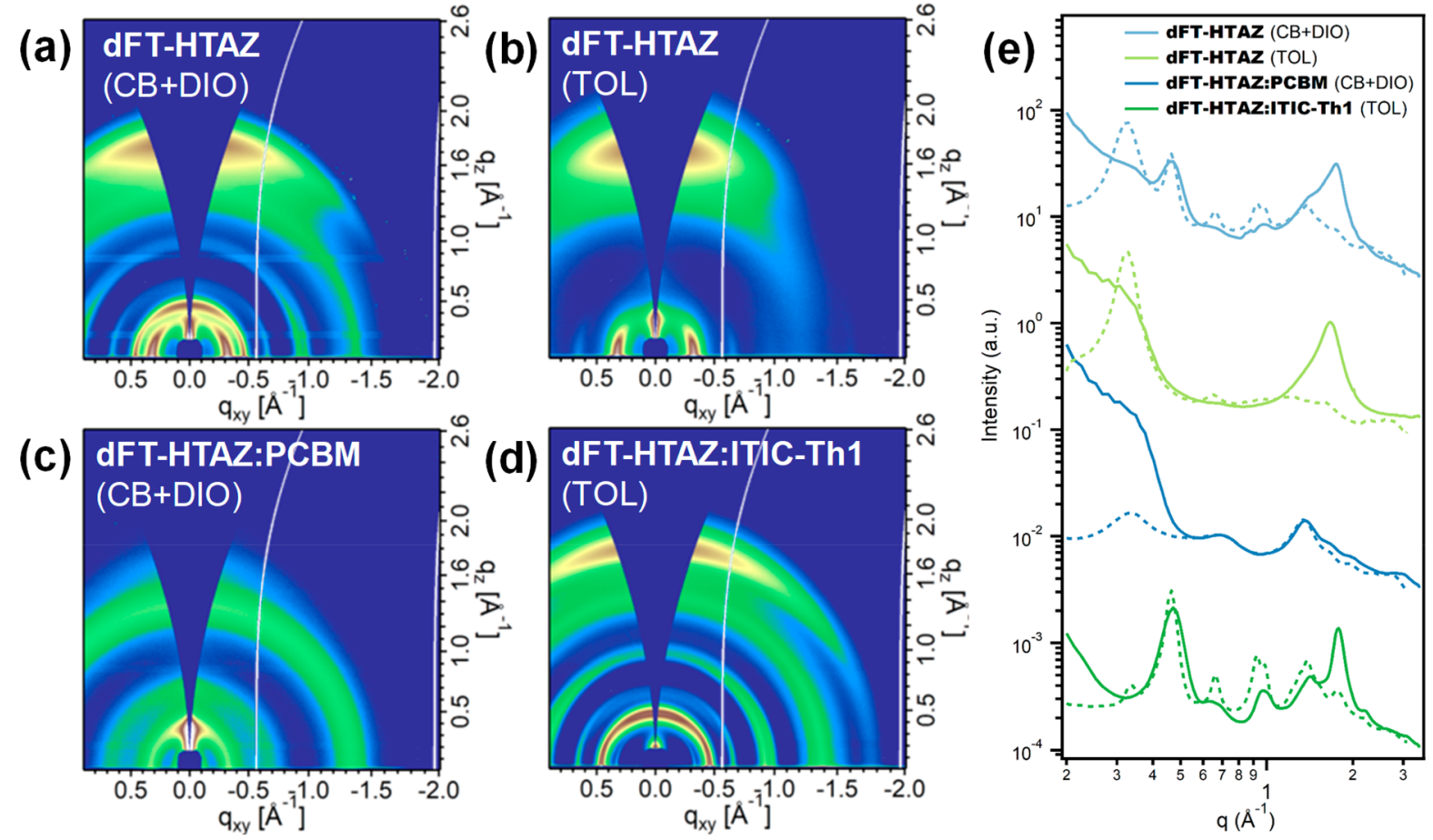

Figure 4. 2D GIWAXS patterns for (a) neat dFT-HTAZ cast from chlorobenzene (CB) with 3\% 1,8-diiodooctane (DIO) additive, (b) neat dFTHTAZ cast from toluene, (c) blend film of dFT-HTAZ:PCBM cast from CB+DIO, (d) blend film of dFT-HTAZ:ITIC-Th1 cast from toluene, and (e) corresponding linecuts for each. The 1D profiles have both in-plane $q_{x y}$ (dotted lines) and out-of-plane $q_{z}$ (solid lines) directions shown.

Table 3. Summary of Morphology Results: (010) Peak Distances and Corresponding Coherence Length from GIWAXS, along with Long Period and Average Phase Purity from RSoXS

\begin{tabular}{|c|c|c|c|c|c|c|}
\hline & $\begin{array}{l}\text { processing } \\
\text { solvent }\end{array}$ & $\begin{array}{c}\text { dFT-HTAZ (010) peak } \\
\left(\AA^{-1}\right)\end{array}$ & $\underset{(\AA)}{\pi-\pi \text { stacking distance }}$ & $\begin{array}{l}\text { (010) peak coherence length } \\
(\AA)\end{array}$ & $\begin{array}{l}\text { long period } \\
(\mathrm{nm})\end{array}$ & $\sigma^{a}$ \\
\hline dFT-HTAZ & $\mathrm{CB}+\mathrm{DIO}$ & 1.73 & 3.63 & 23.4 & & \\
\hline dFT-HTAZ & TOL & 1.67 & 3.76 & 22.4 & & \\
\hline dFT-HTAZ:PCBM & $\mathrm{CB}+\mathrm{DIO}$ & 1.66 & 3.78 & 27.3 & 34.7 & 1.00 \\
\hline dFT-HTAZ:ITIC-Th1 & TOL & 1.78 & 3.53 & 35.3 & 35.9 & 0.73 \\
\hline
\end{tabular}

$\sim 60 \mathrm{~nm} .{ }^{11}$ Additionally, HTAZ blends have generally shown lower relative domain purity compared to the fluorinated alternatives, which can help explain the lower FF values which are seen when comparing HTAZ and dFT-HTAZ blends.

Finally, we want to draw attention to an important comparison: the HTAZ:ITIC-Th1 and dFT-HTAZ:ITICTh1 solar cells. Much like with the PCBM acceptor based devices as we discussed earlier, when ITIC-Th1 was used as the acceptor, the dFT-HTAZ blend has a much higher $V_{\text {oc }}$ $(0.991 \pm 0.002 \mathrm{~V})$ compared to $\operatorname{HTAZ}(0.749 \pm 0.010 \mathrm{~V})-\mathrm{a}$ $32 \%$ increase. The FF was also $60 \%$ higher in the dFT-HTAZ $(57.1 \pm 0.6 \%)$ compared to the HTAZ $(35.8 \pm 1.2 \%)$ blend. The increase in $V_{\mathrm{oc}}$ and FF can be explained by using the same reasoning when comparing the HTAZ:PCBM and dFTHTAZ:PCBM blends (vide supra). The deeper HOMO energy level of dFT-HTAZ can allow for the higher $V_{\text {oc }}$ and the improved planarity from the fluorine interactions can boost the FF and mobility values nearly 6 times higher (dFTHTAZ:ITIC-Th1 with $6.27 \times 10^{-4} \mathrm{~cm}^{2} \mathrm{~V}^{-1} \mathrm{~s}^{-1}$ while HTAZ:ITIC-Th1 has $1.09 \times 10^{-4} \mathrm{~cm}^{2} \mathrm{~V}^{-1} \mathrm{~s}^{-1}$ ). Interestingly, when paired with ITIC-Th1, the HTAZ blend does not show the same level of improvement in terms of $J_{s c}$ as the dFTHTAZ blend does. This is likely due to the fact that the HTAZ had lower mobility values, saturated photocurrent, and charge collection probability when paired with NFAs, as we previously explored. ${ }^{11}$ Because HTAZ has worse charge transport and extraction, the $J_{s c}$ values for the HTAZ:ITIC-Th1 blend (11.77 $\left.\pm 0.72 \mathrm{~mA} / \mathrm{cm}^{2}\right)$ are much lower than dFT-HTAZ (16.12 \pm $\left.0.97 \mathrm{~mA} / \mathrm{cm}^{2}\right)$. As the dFT-HTAZ showed improved $V_{\text {oc }} J_{\mathrm{sc}}$ and $F F$ values compared to HTAZ, the overall efficiency is significantly higher. In fact, the champion dFT-HTAZ:ITICTh1 solar cell device had an efficiency of $9.76 \%$, an astounding $176 \%$ increase compared to the champion HTAZ:ITIC-Th1 device of only $3.54 \%$. This nearly $3 \times$ better performance from the $\mathrm{dFT}$ units demonstrates the effectiveness of this design strategy.

\section{CONCLUSION}

A new conjugated polymer, dFT-HTAZ, was synthesized and characterized to better understand the impact that difluorinated thiophene units have on the performance of conjugated polymer based organic solar cells. Using HTAZ and dFTHTAZ as model conjugated polymers, we demonstrate that fluorination of the thiophene linkers used to connect the donor and acceptor moieties in typical conjugated copolymers can lead to a nearly $3 \times$ improvement in device performance in our particular system. The observed increase in $V_{\text {oc }}$ upon 
fluorination-in PCBM, ITIC, and ITIC-Th1 based devicescan be attributed to the deeper HOMO level introduced by the difluorinated thiophene linkers (dFT). Furthermore, upon comparison of the ITIC-Th1 based devices, dFT-HTAZ has substantially improved FF (60\% higher) and $J_{\text {sc }}$ (37\% higher), which is explained through the increased planarity and mobility values offered by the dFT unit. One important caveat with using the dFT units is the significant deepening of energy levels, which makes pairing with acceptors and transport layers necessary. The results of this study demonstrate that the dFT units are a viable method to further increase efficiency of organic solar cells, and dFT units can be especially useful for polymers that do not have locations for fluorination on the acceptor moiety.

\section{ASSOCIATED CONTENT}

\section{S Supporting Information}

The Supporting Information is available free of charge on the ACS Publications website at DOI: 10.1021/acs.macromol.9b01168.

Synthetic details for monomers and polymer, ${ }^{1} \mathrm{H}$ and ${ }^{19} \mathrm{~F}$ NMR spectra, characterization methods and device fabrication, DFT calculations, SCLC measurements, neat ITIC-Th1 GIWAXS, RSoXS profile, and line fitting for GIWAXS blends (PDF)

\section{AUTHOR INFORMATION}

\section{Corresponding Author}

*E-mail: wyou@unc.edu.

ORCID $\odot$

Jeromy J. Rech: 0000-0001-7963-9357

Liang Yan: 0000-0003-4122-7466

Xiaowei Zhan: 0000-0002-1006-3342

Wei You: 0000-0003-0354-1948

Notes

The authors declare no competing financial interest.

\section{ACKNOWLEDGMENTS}

We thank the NSF (CBET-1639429) for financial support. The authors thank Jianfei $\mathrm{Qu}$ and Prof. Feng He at Southern University of Science and Technology for the HT-GPC measurements. The authors also thank Shubin Liu (Research Computing Center at University of North Carolina at Chapel Hill) for help with the DFT calculations. GIWAXS measurements and analysis are supported by NSF (CBET-1639429). GIWAXS data were acquired at beamline 7.3.3, at the Advanced Light Source (ALS) in Berkeley National Lab, which is supported by the U.S. Department of Energy (No. DE-AC02-05CH11231).

\section{REFERENCES}

(1) Zhou, H.; Yang, L.; You, W. Rational Design of High Performance Conjugated Polymers for Organic Solar Cells. Macromolecules 2012, 45, 607-632.

(2) Ostroverkhova, O. Organic Optoelectronic Materials: Mechanisms and Applications. Chem. Rev. 2016, 116, 13279-13412.

(3) Kietzke, T. Recent Advances in Organic Solar Cells. Adv. OptoElectron. 2007, 2007, 1-15.

(4) Kippelen, B.; Brédas, J.-L. Organic photovoltaics. Energy Environ. Sci. 2009, 2, 251.

(5) Dey, S. Recent Progress in Molecular Design of Fused Ring Electron Acceptors for Organic Solar Cells. Small 2019, 15, 1900134.
(6) Bi, P.; Hao, X. Versatile Ternary Approach for Novel Organic Solar Cells: A Review (Solar RRL 1/2019). Sol. RRL 2019, 3, 1970011.

(7) Gasparini, N.; Salleo, A.; McCulloch, I.; Baran, D. The role of the third component in ternary organic solar cells. Nat. Rev. Mater. 2019, 4, 229-242.

(8) Liu, G.; Jia, J.; Zhang, K.; Jia, X.; Yin, Q.; Zhong, W.; Li, L.; Huang, F.; Cao, Y. 15\% Efficiency Tandem Organic Solar Cell Based on a Novel Highly Efficient Wide-Bandgap Nonfullerene Acceptor with Low Energy Loss. Adv. Energy Mater. 2019, 9, 1803657.

(9) Gurney, R. S.; Lidzey, D. G.; Wang, T. A review of non-fullerene polymer solar cells: from device physics to morphology control. Rep. Prog. Phys. 2019, 82, 036601.

(10) Price, S. C.; Stuart, A. C.; Yang, L.; Zhou, H.; You, W. Fluorine Substituted Conjugated Polymer of Medium Band Gap Yields 7\% Efficiency in Polymer-Fullerene Solar Cells. J. Am. Chem. Soc. 2011, 133, 4625-4631.

(11) Bauer, N.; Zhang, Q.; Zhu, J.; Peng, Z.; Yan, L.; Zhu, C.; Ade, H.; Zhan, X.; You, W. Donor polymer fluorination doubles the efficiency in non-fullerene organic photovoltaics. J. Mater. Chem. A 2017, 5, 22536-22541.

(12) Son, H. J.; Wang, W.; Xu, T.; Liang, Y.; Wu, Y.; Li, G.; Yu, L. Synthesis of Fluorinated Polythienothiophene- co -benzodithiophenes and Effect of Fluorination on the Photovoltaic Properties. J. Am. Chem. Soc. 2011, 133, 1885-1894.

(13) Li, Z.; Zhang, T.; Xin, Y.; Zhao, X.; Yang, D.; Wu, F.; Yang, X. Synergistic effect of fluorination and regio-regularity on the long-term thermal stability of polymer solar cells. J. Mater. Chem. A 2016, 4, $18598-18606$.

(14) Oh, J.; Kranthiraja, K.; Lee, C.; Gunasekar, K.; Kim, S.; Ma, B.; Kim, B. J.; Jin, S.-H. Side-Chain Fluorination: An Effective Approach to Achieving High-Performance All-Polymer Solar Cells with Efficiency Exceeding 7\%. Adv. Mater. 2016, 28, 10016-10023.

(15) Yang, L.; Tumbleston, J. R.; Zhou, H.; Ade, H.; You, W. Disentangling the impact of side chains and fluorine substituents of conjugated donor polymers on the performance of photovoltaic blends. Energy Environ. Sci. 2013, 6, 316-326.

(16) Du, Z.; Bao, X.; Li, Y.; Liu, D.; Wang, J.; Yang, C.; Wimmer, R.; Städe, L. W.; Yang, R.; Yu, D. Balancing High Open Circuit Voltage over $1.0 \mathrm{~V}$ and High Short Circuit Current in BenzodithiopheneBased Polymer Solar Cells with Low Energy Loss: A Synergistic Effect of Fluorination and Alkylthiolation. Adv. Energy Mater. 2018, 8, 1701471.

(17) Roy, C.; Bura, T.; Beaupré, S.; Légaré, M.-A.; Sun, J.-P.; Hill, I. G.; Leclerc, M. Fluorinated Thiophene-Based Synthons: Polymerization of 1,4-Dialkoxybenzene and Fluorinated Dithieno-2,1,3benzothiadiazole by Direct Heteroarylation. Macromolecules 2017, 50, 4658-4667.

(18) Kim, I.-B.; Jang, S.-Y.; Kim, Y.-A.; Kang, R.; Kim, I.-S.; Ko, D.K.; Kim, D.-Y. The Effect of Fluorine Substitution on the Molecular Interactions and Performance in Polymer Solar Cells. ACS Appl. Mater. Interfaces 2017, 9, 24011-24019.

(19) Feng, K.; Yang, G.; Xu, X.; Zhang, G.; Yan, H.; Awartani, O.; Ye, L.; Ade, H.; Li, Y.; Peng, Q. High-Performance Wide Bandgap Copolymers Using an EDOT Modified Benzodithiophene Donor Block with 10.11\% Efficiency. Adv. Energy Mater. 2018, 8, 1602773.

(20) Kelly, M. A.; Roland, S.; Zhang, Q.; Lee, Y.; Kabius, B.; Wang, Q.; Gomez, E. D.; Neher, D.; You, W. Incorporating Fluorine Substitution into Conjugated Polymers for Solar Cells: Three Different Means, Same Results. J. Phys. Chem. C 2017, 121, 20592068.

(21) Zhang, Q.; Yan, L.; Jiao, X.; Peng, Z.; Liu, S.; Rech, J. J.; Klump, E.; Ade, H.; So, F.; You, W. Fluorinated Thiophene Units Improve Photovoltaic Device Performance of Donor-Acceptor Copolymers. Chem. Mater. 2017, 29, 5990-6002.

(22) Huang, H.; Yang, L.; Facchetti, A.; Marks, T. J. Organic and Polymeric Semiconductors Enhanced by Noncovalent Conformational Locks. Chem. Rev. 2017, 117, 10291-10318. 
(23) Mueller, C. J.; Gann, E.; Singh, C. R.; Thelakkat, M.; McNeill, C. R. Control of Molecular Orientation in Polydiketopyrrolopyrrole Copolymers via Diffusive Noncovalent Interactions. Chem. Mater. 2016, 28, 7088-7097.

(24) Park, S.; Cho, J.; Ko, M. J.; Chung, D. S.; Son, H. J. Synthesis and Charge Transport Properties of Conjugated Polymers Incorporating Difluorothiophene as a Building Block. Macromolecules 2015, 48 (12), 3883-3889.

(25) Cheng, Y.; Qi, Y.; Tang, Y.; Zheng, C.; Wan, Y.; Huang, W.; Chen, R. Controlling Intramolecular Conformation through Nonbonding Interaction for Soft-Conjugated Materials: Molecular Design and Optoelectronic Properties. J. Phys. Chem. Lett. 2016, 7, 36093615.

(26) Carsten, B.; Szarko, J. M.; Son, H. J.; Wang, W.; Lu, L.; He, F.; Rolczynski, B. S.; Lou, S. J.; Chen, L. X.; Yu, L. Examining the Effect of the Dipole Moment on Charge Separation in Donor-Acceptor Polymers for Organic Photovoltaic Applications. J. Am. Chem. Soc. 2011, 133, 20468-20475.

(27) Xia, D.; Wu, Y.; Wang, Q.; Zhang, A.; Li, C.; Lin, Y.; Colberts, F. J. M.; van Franeker, J. J.; Janssen, R. A. J.; Zhan, X.; Hu, W.; Tang, Z.; Ma, W.; Li, W. Effect of Alkyl Side Chains of Conjugated Polymer Donors on the Device Performance of Non-Fullerene Solar Cells. Macromolecules 2016, 49, 6445-6454.

(28) Zhang, A.; Xiao, C.; Wu, Y.; Li, C.; Ji, Y.; Li, L.; Hu, W.; Wang, Z.; Ma, W.; Li, W. Effect of Fluorination on Molecular Orientation of Conjugated Polymers in High Performance Field-Effect Transistors. Macromolecules 2016, 49, 6431-6438.

(29) Jo, J. W.; Bae, S.; Liu, F.; Russell, T. P.; Jo, W. H. Comparison of Two D-A Type Polymers with Each Being Fluorinated on D and A Unit for High Performance Solar Cells. Adv. Funct. Mater. 2015, 25, $120-125$.

(30) Jo, J. W.; Jung, J. W.; Jung, E. H.; Ahn, H.; Shin, T. J.; Jo, W. H. Fluorination on both $\mathrm{D}$ and $\mathrm{A}$ units in $\mathrm{D}-\mathrm{A}$ type conjugated copolymers based on difluorobithiophene and benzothiadiazole for highly efficient polymer solar cells. Energy Environ. Sci. 2015, 8, 2427-2434.

(31) Jo, J. W.; Jung, J. W.; Wang, H.; Kim, P.; Russell, T. P.; Jo, W. $\mathrm{H}$. Fluorination of Polythiophene Derivatives for High Performance Organic Photovoltaics. Chem. Mater. 2014, 26, 4214-4220.

(32) Zhang, H.; Li, S.; Xu, B.; Yao, H.; Yang, B.; Hou, J. Fullerenefree polymer solar cell based on polythiophene derivative with an unprecedented energy loss less than $0.5 \mathrm{eV}$. J. Mater. Chem. A 2016, 4, 18043-18049.

(33) Zhang, S.; Qin, Y.; Uddin, M. A.; Jang, B.; Zhao, W.; Liu, D.; Woo, H. Y.; Hou, J. A Fluorinated Polythiophene Derivative with Stabilized Backbone Conformation for Highly Efficient Fullerene and Non-Fullerene Polymer Solar Cells. Macromolecules 2016, 49, 29933000.

(34) He, D.; Geng, X.; Ding, L. The effect of fluorination on the photovoltaic performance of the $\mathrm{D}-\mathrm{A}$ copolymers containing naphtho[2,3-c]thiophene-4,9-dione and bithiophene moieties. Polym. Chem. 2016, 7, 4993-4997.

(35) Wang, Z.; Li, Z.; Liu, J.; Mei, J.; Li, K.; Li, Y.; Peng, Q. Solution-Processable Small Molecules for High-Performance Organic Solar Cells with Rigidly Fluorinated 2,2'-Bithiophene Central Cores. ACS Appl. Mater. Interfaces 2016, 8, 11639-11648.

(36) Jung, E. H.; Ahn, H.; Jo, W. H.; Jo, J. W.; Jung, J. W. Isoindigobased conjugated polymer for high-performance organic solar cell with a high VOC of $1.06 \mathrm{~V}$ as processed from non-halogenated solvent. Dyes Pigm. 2019, 161, 113-118.

(37) Kim, J. J.-H.; Park, J. B.; Lee, W.-H.; Kim, J. J.-H.; Hwang, D.H.; Kang, I. High-performance fluorine-containing BDT-based copolymer for organic solar cells with a high open circuit voltage. J. Polym. Sci., Part A: Polym. Chem. 2017, 55, 2506-2512.

(38) Cho, S.; Lee, W.; Park, J. B.; Kim, J.; Hwang, D.; Kang, I. Synthesis and characterization of fluorine atom substituted new BDTbased polymers for use in organic solar cells. Synth. Met. 2015, 210, 273-281.
(39) Fan, Q.; Su, W.; Guo, X.; Wang, Y.; Chen, J.; Ye, C.; Zhang, M.; Li, Y. Side-chain engineering for efficient non-fullerene polymer solar cells based on a wide-bandgap polymer donor. J. Mater. Chem. A 2017, 5, 9204-9209.

(40) Xue, L.; Yang, Y.; Xu, J.; Zhang, C.; Bin, H.; Zhang, Z.; Qiu, B.; Li, X.; Sun, C.; Gao, L.; Yao, J.; Chen, X.; Yang, Y.; Xiao, M.; Li, Y. Side Chain Engineering on Medium Bandgap Copolymers to Suppress Triplet Formation for High-Efficiency Polymer Solar Cells. Adv. Mater. 2017, 29, 1703344.

(41) Feng, K.; Yuan, J.; Bi, Z.; Ma, W.; Xu, X.; Zhang, G.; Peng, Q. Low-Energy-Loss Polymer Solar Cells with $14.52 \%$ Efficiency Enabled by Wide-Band-Gap Copolymers. iScience 2019, 12, 1-12.

(42) Yang, J.; Cong, P.; Chen, L.; Wang, X.; Li, J.; Tang, A.; Zhang, B.; Geng, Y.; Zhou, E. Introducing Fluorine and Sulfur Atoms into Quinoxaline-Based p-type Polymers To Gradually Improve the Performance of Fullerene-Free Organic Solar Cells. ACS Macro Lett. 2019, 8, 743-748.

(43) Chen, H.-C.; Chen, Y.; Liu, C.; Chien, Y.; Chou, S.-W.; Chou, P. Prominent Short-Circuit Currents of Fluorinated QuinoxalineBased Copolymer Solar Cells with a Power Conversion Efficiency of 8.0\%. Chem. Mater. 2012, 24, 4766-4772.

(44) Wang, Z.; Zhao, J.; Li, Y.; Peng, Q. Low band-gap copolymers derived from fluorinated isoindigo and dithienosilole: synthesis, properties and photovoltaic applications. Polym. Chem. 2014, 5, 4984-4992.

(45) Bronstein, H.; Frost, J. M.; Hadipour, A.; Kim, Y.; Nielsen, C. B.; Ashraf, R. S.; Rand, B. P.; Watkins, S.; McCulloch, I. Effect of Fluorination on the Properties of a Donor-Acceptor Copolymer for Use in Photovoltaic Cells and Transistors. Chem. Mater. 2013, 25, $277-285$.

(46) Zhou, H.; Yang, L.; Stuart, A. C.; Price, S. C.; Liu, S.; You, W. Development of Fluorinated Benzothiadiazole as a Structural Unit for a Polymer Solar Cell of 7\% Efficiency. Angew. Chem., Int. Ed. 2011, 50, 2995-2998.

(47) Chen, Z.; Yan, L.; Rech, J. J.; Hu, J.; Zhang, Q.; You, W. GreenSolvent-Processed Conjugated Polymers for Organic Solar Cells: The Impact of Oligoethylene Glycol Side Chains. ACS Appl. Polym. Mater. 2019, 1, 804-814.

(48) Qian, D.; Ye, L.; Zhang, M.; Liang, Y.; Li, L.; Huang, Y.; Guo, X.; Zhang, S.; Tan, Z.; Hou, J. Design, Application, and Morphology Study of a New Photovoltaic Polymer with Strong Aggregation in Solution State. Macromolecules 2012, 45, 9611-9617.

(49) Bura, T.; Beaupré, S.; Ibraikulov, O. A.; Légaré, M.-A.; Quinn, J.; Lévêque, P.; Heiser, T.; Li, Y.; Leclerc, N.; Leclerc, M. New Fluorinated Dithienyldiketopyrrolopyrrole Monomers and Polymers for Organic Electronics. Macromolecules 2017, 50, 7080-7090.

(50) Guo, K.; Bai, J.; Jiang, Y.; Wang, Z.; Sui, Y.; Deng, Y.; Han, Y.; Tian, H.; Geng, Y. Diketopyrrolopyrrole-Based Conjugated Polymers Synthesized via Direct Arylation Polycondensation for High Mobility Pure n-Channel Organic Field-Effect Transistors. Adv. Funct. Mater. 2018, 28, 1801097.

(51) Yang, C.; Jin, W.; Wang, J.; Ding, Y.; Nong, S.; Shi, K.; Lu, Y.; Dai, Y.; Zhuang, F.; Lei, T.; Di, C.; Zhu, D.; Wang, J.; Pei, J. Enhancing the n-Type Conductivity and Thermoelectric Performance of Donor-Acceptor Copolymers through Donor Engineering. Adv. Mater. 2018, 30, 1802850.

(52) Mueller, C. J.; Singh, C. R.; Fried, M.; Huettner, S.; Thelakkat, M. High Bulk Electron Mobility Diketopyrrolopyrrole Copolymers with Perfluorothiophene. Adv. Funct. Mater. 2015, 25, 2725-2736.

(53) Gao, Y.; Deng, Y.; Tian, H.; Zhang, J.; Yan, D.; Geng, Y.; Wang, F. Multifluorination toward High-Mobility Ambipolar and Unipolar n-Type Donor-Acceptor Conjugated Polymers Based on Isoindigo. Adv. Mater. 2017, 29, 1606217.

(54) Zhang, L.; Wang, Z.; Duan, C.; Wang, Z.; Deng, Y.; Xu, J.; Huang, F.; Cao, Y. Conjugated Polymers Based on Thiazole Flanked Naphthalene Diimide for Unipolar n-Type Organic Field-Effect Transistors. Chem. Mater. 2018, 30, 8343-8351.

(55) Chen, H.; Nikolka, M.; Wadsworth, A.; Yue, W.; Onwubiko, A.; Xiao, M.; White, A. J. P.; Baran, D.; Sirringhaus, H.; McCulloch, I. A 
Thieno[2,3- b ]pyridine-Flanked Diketopyrrolopyrrole Polymer as an n-Type Polymer Semiconductor for All-Polymer Solar Cells and Organic Field-Effect Transistors. Macromolecules 2018, 51, 71-79.

(56) Ni, Z.; Dong, H.; Wang, H.; Ding, S.; Zou, Y.; Zhao, Q.; Zhen, Y.; Liu, F.; Jiang, L.; Hu, W. Quinoline-Flanked Diketopyrrolopyrrole Copolymers Breaking through Electron Mobility over $6 \mathrm{~cm} 2 \mathrm{~V}-1 \mathrm{~s}$ - 1 in Flexible Thin Film Devices. Adv. Mater. 2018, 30, 1704843.

(57) Chen, F.; Jiang, Y.; Sui, Y.; Zhang, J.; Tian, H.; Han, Y.; Deng, Y.; Hu, W.; Geng, Y. Donor-Acceptor Conjugated Polymers Based on Bisisoindigo: Energy Level Modulation toward Unipolar n-Type Semiconductors. Macromolecules 2018, 51, 8652-8661.

(58) Crouch, D. J.; Sparrowe, D.; Heeney, M.; McCulloch, I.; Skabara, P. J. Polyterthiophenes Incorporating 3,4-Difluorothiophene Units: Application in Organic Field-Effect Transistors. Macromol. Chem. Phys. 2010, 211, 2642-2648.

(59) Ni, Z.; Dong, H.; Wang, H.; Ding, S.; Zou, Y.; Zhao, Q.; Zhen, Y.; Liu, F.; Jiang, L.; Hu, W. Quinoline-Flanked Diketopyrrolopyrrole Copolymers Breaking through Electron Mobility over $6 \mathrm{~cm}^{2} \mathrm{~V}^{-1} \mathrm{~s}^{-1}$ in Flexible Thin Film Devices. Adv. Mater. 2018, 30, 1704843.

(60) Kawashima, K.; Fukuhara, T.; Suda, Y.; Suzuki, Y.; Koganezawa, T.; Yoshida, H.; Ohkita, H.; Osaka, I.; Takimiya, K. Implication of Fluorine Atom on Electronic Properties, Ordering Structures, and Photovoltaic Performance in NaphthobisthiadiazoleBased Semiconducting Polymers. J. Am. Chem. Soc. 2016, 138, 10265-10275.

(61) Fei, Z.; Shahid, M.; Yaacobi-Gross, N.; Rossbauer, S.; Zhong, H.; Watkins, S. E.; Anthopoulos, T. D.; Heeney, M. Thiophene fluorination to enhance photovoltaic performance in low band gap donor-acceptor polymers. Chem. Commun. 2012, 48, 11130.

(62) Collado-Fregoso, E.; Boufflet, P.; Fei, Z.; Gann, E.; Ashraf, S.; Li, Z.; McNeill, C. R.; Durrant, J. R.; Heeney, M. Increased Exciton Dipole Moment Translates into Charge-Transfer Excitons in Thiophene-Fluorinated Low-Bandgap Polymers for Organic Photovoltaic Applications. Chem. Mater. 2015, 27, 7934-7944.

(63) Wolf, J.; Cruciani, F.; El Labban, A.; Beaujuge, P. M. Wide Band-Gap 3,4-Difluorothiophene-Based Polymer with 7\% Solar Cell Efficiency: An Alternative to P3HT. Chem. Mater. 2015, 27, 41844187.

(64) Liu, S.; Song, X.; Thomas, S.; Kan, Z.; Cruciani, F.; Laquai, F.; Bredas, J.-L.; Beaujuge, P. M. Thieno[3,4- $c$ ]Pyrrole-4,6-Dione-Based Polymer Acceptors for High Open-Circuit Voltage All-Polymer Solar Cells. Adv. Energy Mater. 2017, 7, 1602574.

(65) Liu, S.; Kan, Z.; Thomas, S.; Cruciani, F.; Brédas, J.-L.; Beaujuge, P. M. Thieno[3,4- c ] pyrrole-4,6-dione-3,4-difluorothiophene Polymer Acceptors for Efficient All-Polymer Bulk Heterojunction Solar Cells. Angew. Chem., Int. Ed. 2016, 55, 12996-13000.

(66) Wadsworth, A.; Moser, M.; Marks, A.; Little, M. S.; Gasparini, N.; Brabec, C. J.; Baran, D.; McCulloch, I. Critical review of the molecular design progress in non-fullerene electron acceptors towards commercially viable organic solar cells. Chem. Soc. Rev. 2019, 48, $1596-1625$

(67) Lin, Y.; Zhan, X. Non-fullerene acceptors for organic photovoltaics: an emerging horizon. Mater. Horiz. 2014, 1, 470.

(68) Yan, C.; Barlow, S.; Wang, Z.; Yan, H.; Jen, A. K.-Y.; Marder, S. R.; Zhan, X. Non-fullerene acceptors for organic solar cells. Nat. Rev. Mater. 2018, 3, 18003.

(69) He, D.; Zhao, F.; Xin, J.; Rech, J. J.; Wei, Z.; Ma, W.; You, W.; Li, B.; Jiang, L.; Li, Y.; Wang, C. A Fused Ring Electron Acceptor with Decacyclic Core Enables over 13.5\% Efficiency for Organic Solar Cells. Adv. Energy Mater. 2018, 8, 1802050.

(70) Zhang, J.; Tan, H. S.; Guo, X.; Facchetti, A.; Yan, H. Material insights and challenges for non-fullerene organic solar cells based on small molecular acceptors. Nat. Energy 2018, 3, 720-731.

(71) Cheng, P.; Li, G.; Zhan, X.; Yang, Y. Next-generation organic photovoltaics based on non-fullerene acceptors. Nat. Photonics 2018, 12, 131-142.

(72) Pattanasattayavong, P.; Yaacobi-Gross, N.; Zhao, K.; Ndjawa, G. O. N.; Li, J.; Yan, F.; O’Regan, B. C.; Amassian, A.; Anthopoulos, T. D. Hole-Transporting Transistors and Circuits Based on the
Transparent Inorganic Semiconductor Copper(I) Thiocyanate (CuSCN) Processed from Solution at Room Temperature. Adv. Mater. 2013, 25, 1504-1509.

(73) Li, W.; Albrecht, S.; Yang, L.; Roland, S.; Tumbleston, J. R.; McAfee, T.; Yan, L.; Kelly, M. A.; Ade, H.; Neher, D.; You, W. Mobility-Controlled Performance of Thick Solar Cells Based on Fluorinated Copolymers. J. Am. Chem. Soc. 2014, 136, 15566-15576.

(74) Fan, B.; Zhang, D.; Li, M.; Zhong, W.; Zeng, Z.; Ying, L.; Huang, F.; Cao, Y. Achieving over $16 \%$ efficiency for single-junction organic solar cells. Sci. China: Chem. 2019, 62, 746-752.

(75) Zhao, F.; Dai, S.; Wu, Y.; Zhang, Q.; Wang, J.; Jiang, L.; Ling, Q.; Wei, Z.; Ma, W.; You, W.; Wang, C.; Zhan, X. Single-Junction Binary-Blend Nonfullerene Polymer Solar Cells with $12.1 \%$ Efficiency. Adv. Mater. 2017, 29, 1700144.

(76) Lin, Y.; Wang, J.; Zhang, Z.-G.; Bai, H.; Li, Y.; Zhu, D.; Zhan, $X$. An Electron Acceptor Challenging Fullerenes for Efficient Polymer Solar Cells. Adv. Mater. 2015, 27, 1170-1174.

(77) Hexemer, A.; Bras, W.; Glossinger, J.; Schaible, E.; Gann, E.; Kirian, R.; MacDowell, A.; Church, M.; Rude, B.; Padmore, H. A SAXS/WAXS/GISAXS Beamline with Multilayer Monochromator. J. Phys. Conf. Ser. 2010, 247, 012007.

(78) Gann, E.; Young, A. T.; Collins, B. A.; Yan, H.; Nasiatka, J.; Padmore, H. A.; Ade, H.; Hexemer, A.; Wang, C. Soft x-ray scattering facility at the Advanced Light Source with real-time data processing and analysis. Rev. Sci. Instrum. 2012, 83, 045110.

(79) Ye, L.; Stuard, S. J.; Ade, H. In Conjugated Polymers; CRC Press: 2019; pp 427-458.

(80) Ye, L.; Hu, H.; Ghasemi, M.; Wang, T.; Collins, B. A.; Kim, J.H.; Jiang, K.; Carpenter, J. H.; Li, H.; Li, Z.; McAfee, T.; Zhao, J.; Chen, X.; Lai, J. L. Y.; Ma, T.; Bredas, J.-L.; Yan, H.; Ade, H. Quantitative relations between interaction parameter, miscibility and function in organic solar cells. Nat. Mater. 2018, 17, 253-260.

(81) Zhang, Q.; Kelly, M. A.; Hunt, A.; Ade, H.; You, W. Comparative Photovoltaic Study of Physical Blending of Two Donor-Acceptor Polymers with the Chemical Blending of the Respective Moieties. Macromolecules 2016, 49, 2533-2540. 